\title{
Environmental Factor, Education \& Training and PPE Impact on Safety Performance: A Study Among Construction Workers at SESCO Sub-station, Balingian, Sarawak
}

\author{
Jati Kasuma ${ }^{1}$, Norlida Ismailly ${ }^{2}$, Sara Ghaffari ${ }^{3}$, Muhamad Saufi Che Rusuli ${ }^{4} \&$ Abdul Hakim Abdul Gapor ${ }^{5}$ \\ ${ }^{1}$ Faculty of Business Management, Universiti Teknologi MARA Malaysia, Sarawak Branch, Malaysia \\ ${ }^{2}$ Faculty of Information Management, Universiti Teknologi MARA Malaysia, Sarawak Branch, Malaysia \\ ${ }^{3}$ Faculty of Management, Universiti Teknologi Malaysia, Malaysia \\ ${ }^{4}$ Malaysian Graduate School of Entrepreneurship and Business, Universiti Malaysia Kelantan, Malaysia \\ ${ }^{5}$ Kulliyah of Economics and Management Sciences, International Islamic University Malaysia, Malaysia \\ Correspondence: Jati Kasuma, Senior Lecturer, Faculty of Business Management, Universiti Teknologi MARA \\ Malaysia, Sarawak Branch, Malaysia.
}

Received: May 1, 2019

doi:10.5430/rwe.v10n2p38
Accepted: June 1, 2019

Online Published: July 7, 2019

URL: https://doi.org/10.5430/rwe.v10n2p38

\begin{abstract}
Safety and health at workplace is an emergent concern in almost all parts of the world including developing countries such as Malaysia. Construction industry is one of the most hazardous industries with regard to work-related injury and fatality rates. Impact on the company would include loss working hours of injured employee, cost of repair and replacement of property and damages as well as increment in insurance premium. The purpose of the study is intended to examine the relationship between factors with safety performance at construction sites. This study investigates whether factors such as working environment, education \& training, PPE and weather have any influence on safety performance. The study was conducted among construction workers at Sesco Sub-Station, Balingian, and Sarawak. A set of validated questionnaires were distributed to 100 construction workers. Data were examined based on 95 returned questionnaires (respond rate 95\%). Data were analyzed with SPSS version 22 using descriptive and inferential statistics. Pearson's correlation coefficient was used to measure the strength of relationship between independent and dependent variables. It was concluded that the most important factor affecting safety performance of the construction workers at SESCO Sub-Station, Balingian, and Sarawak is PPE.
\end{abstract}

Keywords: environmental factor, education \& training, personal protective equipment, safety performance, Sarawak electricity supply company

\section{Introduction}

Safety compliance concern individuals who carry out core safety activities to maintain workplace safety, including adhering to safety rules and procedures and wearing personal protective equipment (Griffith \& Neal, 2000). Kelloway \& Francis (2008) outlined that safety compliance is attained when employees pursue safety-related rules and commonly work in an undisruptive manner. The consequence of non-compliance safety behavior such as Chernobyl in 1986 and Bhopal disaster 1984 were due to human factors as reported by Goetsch (2008). Both major disasters were cause to non-compliance with safety behaviors at the workplace that had vast impact to human safety in general.

There is an emergent concern about safety and health at workplace in almost all parts of the world including the developing countries such as Malaysia. To find out the cause that may contribute to work-related accidents, it is important to know the statistic pattern of accidents at the workplace. In Malaysia, the Social Security Organization (SOCSO) of Malaysia as cited from Aziz (2009), it is estimated total losses to fatal accident is equivalent to RM1.2 million losses with reference year in 2008. In addition, payment for disablement was amounted to RM215 million for the same year. These proved that accidents are extremely costly. One could not bear any of lives, and definitely live could not be replaced with anything, be in monetary figure or be it in any other forms of compensations. Insurance company premium will be based on historical evidence and of course, poor safety records will unavoidably reflect in 
the premiums. Loss to a company includes loss working hours of an injured employee, cost of repair and for replacement of property and damages and also increment in insurance premium.

The construction industry has been identified as one of the most hazardous industries in many parts of the world, as measured by work-related mortality, workers' compensation, injury and fatality rates (Ling, Liu \& Woo, 2009). Safety at work is a complex phenomenon and a subjective area of study. This is because industrial safety has undergone significant changes over the past decade (Badri, Gbodossou \& Nadeau, 2012). However, the construction sector is notable as it continues to register a high rate of accident-related casualties. Construction workers who work within the construction industry face a greater risk of fatality than workers in other industries (Bansal, 2011).

Accidents at workplace are more expensive than many managers realized (Roughton \& Mercurio, 2002). This is because there are many hidden costs that are not truly understood. Some costs are obvious while other costs are transparent- workers' compensation claim over medical costs and indemnity payments for an injured employee. These are direct cost of incident. However, what about the costs to train and compensate a replacement employee, repair damaged property or equipment, downtime of equipment, investigating the incident and implementing corrective actions? Even less apparent are the costs related to product schedule delays, added administrative time, lower moral, increased absenteeism, pain and suffering of employee and impaired customer relation. These are the indirect costs and as such, have been described by many professionals as an iceberg. According to OSHA USA, studies shows that the ratio of indirect cost to direct cost can vary widely from a high ratio of 20:1 to as low of 1:1.

Generally, at the national level, even though the trend is decreasing, from the accident analysis, one of the most common causes of accident is high number of non-compliance to safety requirement by contractor workers. Non-compliance to safety requirement by contractor worker shall be the focus and the research framework of this research paper to ensure that excellent record is not demolished. It was clearly stated in the OSH Act 1994, that safety accountability to any person who works with the main company, lies on the main company itself. The operational workers were directly exposed to loads of hazards such as mechanical hazard, electrical hazard and other related hazards. These hazards can be identified at the preliminary work by using the Job Hazard Analysis (JHA).

Non-compliance to safety standards and requirement committed by many individuals were known to be either unintentional or intentional as they do their jobs and operate any machine simply because they have seen it done a million times and has never had a bad experience or they just break the set rules and cut corners in order to get the job done faster. Though most of these tasks may be minor, and often considered temporary, they should be performed in a safe, correct and appropriate manner and according to all applicable codes and standards.

In SESCO Sub-Station Project at Balingian, if injuries or accident happened, it needs to be reported and some required further investigation need to be conducted by safety unit. From the incident investigation findings, recommendations were made to prevent reoccurrence by putting corrective and preventive actions. Even though the root causes of the accident were normally relating to the latent failure or absence system, procedure and standard, but it was very clear that the direct causes of accidents were mostly related to the above-mentioned factors. Hence, this study aims to investigate the relationship and strength of working environment, education \& training and PPE towards safety performance among Construction workers at SESCO Sub-Station, Balingian, Sarawak.

\section{Literature Review}

\subsection{Empirical Studies on Safety Performance}

There is a significant relationship between safety performances for example compliance with safe working practices and accidents occur had been a common feature in literatures related to safety at workplace in various field of employment. According to Neal et al (2000), most of the studies had found affirmative relationships between self-reported safety practices and safety climate where in turn both variables were negatively related to accidents frequency. This explained that when compliance with safety practices diminished, it was the result of improper management of safety climate where finally contributed to higher accidents rates. From the perceptions perspective, safety climate comprises organizational safety policies and work procedures, which derive from organizational norm principles and expectation, decision making, and safety principles together with organizational obligation to safety manner (Hahn \& Murphy, 2008). High commitment shown by the organization on workplace safety measurement contributed to positive perceptions regarding working environment.

Kelloway \& Francis (2008) supported the above-mentioned factors and suggested management need to have apparent and enacted safety policies in place and must be implemented and planned. As a result, much obedient employees that feels secure in making safety precedence in their own deeds. Meams et al (2003) emphasized that the policy will 
contribute to safe demeanor of the employees. Employees' perception is utmost important due to safety climate has been linked to better adherence to safe work behaviors and few accident related injuries.

From the general review on available literatures, this study will examine safety practices in workplace by adopting Workplace Safety Scale (WSS) develop by Hayes et al (1998) and recently tested by Ratnawills (2010) in her study on 'Understanding Employees Compliance with Safety Behavior in a Telecommunication Industry". This model consisting of five constructs of predictors variables namely job safety, coworker safety, supervisor safety, management safety practices and perception on safety programmed applied by the organization on compliance with safety practices. Further elaboration and discussion on WSS will be briefly placed in the following sections.

\subsection{Environmental Factor}

The environmental factors can be categorized into two main methods in which the environment deals with the effort to improve the safety performance. These two categories are mainly the engineering and the behavioral intervention. Duijm et al (2008) argued that the engineering factors emphasis on reducing and reducing physical hazards within the environment, while behavioral factors base on environment deals with the behaviors of the workers so that the hazardous environment can be improved through interaction.

The construction site is a complex system with a lot of stakeholders working together to complete the construction project. This complex system also includes some information being passed from one team (design) to another (construction), which is required for risk assessment and communication. In the meantime, the physical space, the working procedure (site operation), tools and methods used and resources available are factors influencing risk assessment and communication. This study considers the physical space, instruments, tools and equipment as well as the working team and working procedures as factors in the work environment system (Hakkinen, 1995).

However, the safety engineering which involves environmental factors deals in term of devices such as mechanical guards, personal protective equipment, and ergonomically designed tools and equipment. Safety engineering has found to be successful tools to decrease hazards as reported by Gunawan (2006). They further argued that the engineering factor has major three problems. Firstly, it is extremely extensive and labor intensive, in order to find all the expected hazardous conditions in the occupational environment. Secondly, it may foster unsafe reliance on artificial safety controls and thirdly, the workers might ignore safety devices (Chang \& Yeh, 2005).

Worksite factor is one of the aspects contributing to OSH accidents in construction industry. The first part of the worksite factor that needs to be addressed is the jobsite conditions such as excessive noise, poor illumination, poor ventilation and weather elements (Abdul Hamid et al, 2008). Weather elements can be connected to injuries caused by exposure to extreme temperatures regardless cold or hot (Gangolells et al, 2010). Another aspect of worksite factor is related to poor site management such as housekeeping and site constraints (Reese \& Eidson, 1999). Worksite factor related to the needs of the construction tasks leading to multiple workforces that are transient (constantly changing worksites) and working together on diversity of tasks at the same time in the same project sites is one more aspect that requires an attention (Pinto, Nunes, \& Ribeiro, 2011). The final aspect of worksite factor can be traced to construction materials and equipment. Elements that needed to be focused for this part are the suitability, usability and condition of the materials and equipment due to different causes such as design, specification, supply, availability and maintenance. Examples of unsafe equipment's are the one without safety device, equipment failure and not ergonomics (Abdul Hamid et al, 2008). More than half of the incidents are related to equipment's, meanwhile more than quarter can be traced back to materials (Haslam et al, 2005).

\subsection{Education and Training}

Training and development (TD) define as a process that enables people to acquire new knowledge, learn new skills, and perform behaviors in a new way (Cherrington, 1995). Further distinguishes between training and development by stating that training refers to the acquisition of specific skills or knowledge, and development refers to the improvement of intellectual and emotional ability needed to perform better at a specific job. Therefore, investment in TD of employees improves profitability, organizational culture and is integral in the formation of a lean organization (Inyang, 2008). Safety training is an informal method to help individuals in attaining knowledge, changing attitudes and performing safe work behaviors (Johnston et al, 1994).

It is widely accepted in the construction industry that training plays an important role in worker safety. Worker training typically begins with worker orientation and continues as workers need to become more informed about certain aspects of the work they are doing. These additional training sessions may include topics such as confined space entry, hot work, traffic control, procedures, and a wide assortment of other topics, whether to introduce new information or merely to provide a refresher on a subject, (Hinze \& Gambatese, 2003; Suryanto, Haseeb \& Hartani 2018). 
The provision of safety training for employees is one important aspect for consideration to improve safety performance. A study on the effect of first aid training on Australian construction workers concluded that training has a positive preventive effect on workers to avoid injury. It has also been found that workplace injuries would be reduced if workers received first aid training, (Teo et al, 2005). A formal training program helps personnel to carry out various preventive activities effectively. It also helps establish a positive attitude towards safety and integrates safety into the production and quality goals, (Kartam et al, 2000; Sundjo \& Aziseh 2018).

The training providing safety skill and information should be supplemented by the techniques of persuasion. Persuasion has an important function. The most common form is the poster used to indicate bad habits, pinpoint the advantages of safe working, or give detailed information, advice, or instruction on special points (Al-Amoudi, 1997). Koehn et al (1995) concluded in their research that in developing countries, laborers are not trained in safe work practices, and there tends to be a lack of management commitment to safety programs and various safety procedures.

It is clear that training has a contributing role in defining management practices to enhance safety performance. Providing regular training sessions increase the awareness of employees about hazardous tasks. On the other hand, the safety training is very useful as it allows employees to predict future accidents or near misses.

In order to improve the quality of safety and health in a large scale, the management level should consider a systematic and comprehensive safety approach at construction site. This approach should be clearly explained by specific procedure for each hazardous activity which has been identified in design stage. The process should be clear and understandable for everyone. Moreover, the organization should hold safety and health training program for new employees. This strategy will put the orientation of the organization in a preventive process. Workers who are properly trained would make a correct decision in dealing with accidents associated with their workplace (Vredenburgh, 2002; Obi \& Okekeokosisi 2018). The organization that provides training and constantly inform their employees to adhere to safety regulations may be able to reduce the numbers of probable accidents and injuries at the workplace.

\subsection{Personal Protective Equipment}

Personal Protective Equipment (PPE) refers to protective clothing, helmets, goggles, or other garment designed to protect the wearer's body or clothing from injury by electrical hazards, heat, chemicals, and infection, for job-related occupational safety and health purposes, and in sports, martial arts, combat, etc. There are different types of PPE related to construction. The most common equipment includes head, hand, face, eye, foot, and body protection. Hard hat is required to protect head and neck from injuries. Even though head protection may not protect from every potential blow, it can greatly reduce head injuries. High visibility apparel is another form of PPE that often times is not exercised fully (Obeng, 2018).

There are certain matters that must be taken into consideration when providing appropriate protective equipment to workers. These include how the PPE may cause uneasiness or discomfort to the workers and further become obstruction to their work. The management must be responsible to conduct strict inspection on the proper implementation of PPE at all time. In addition they also have to take into account the high cost of providing PPE. As such there are two categories of PPE. The first category includes the use of safety helmet, safety shoes and suitable working clothing while the second category depending on the kinds of work involved, such as eye protector, protective glove, ear protector and safety belt (Jannadi, 2008; Obay, 2018).

The use of safe machinery and facilities is essential to maintain the health and safety of site personnel. With the advent of technology in the construction industry, the design of machinery and plants had been improved. Technological intervention has resulted in automation and comprehensive facility redesign. Although this approach has reduced the large number of accidents, but at the same time it causes new type of accident. For instance, new workers who are not familiar with the technology of the plants and facilities may cause accidents in construction projects. To overcome this problem new control techniques have emerged in the form of emergency switch operated by workers to control the operation. This system involves a sensor that specifies the existence of workers in the workplace. Another fundamental solution is the proper layout of plant and material at construction projects. With a proper arrangement of machinery and exact layout, a large percentage of hazards will be omitted. In a construction project, the issues of re-design and re-engineering the work station altogether will help to eliminate dangerous incidents.

Another common malpractice in relation to PPE is the lack of use of hearing protection when needed. It is common to observe construction workers wearing their hard hats, appropriate boots and gloves but no hearing protection around noisy operations. It is amazing how easy it is to put a pair of gloves on and yet workers have a difficult time doing so. Foot protection is another one that requires little to no effort. A pair of qualified boots is more than enough to reduce 
the chance of a foot related injury. It does not take much effort to wear the appropriate PPE when working, but still, not all construction workers, constantly wear the correct protection.

Sawacha et al (1999) indicated that the provision and use of the correct type of protective equipment and clothing are only the pre-requisites for improving safety performance. The workers should also be trained for the correct trades or construction tasks. The importance of a clean and tidy site as a factor that improves safety performance cannot be overlooked. Finally, a well-trained safety representative on site can improve safety performance by undertaking fault spotting and insisting on corrective actions being taken

Sawacha et al (1999) also observed that accidents at work occurred either due to lack of knowledge, training or supervision, lack of means to carry out a task safely, errors in judgment, carelessness, laziness or total irresponsibility. In addition, the lack of a controlled working environment and the complexity and diversity of the sizes of the organizations have an effect on safety performance in the industry. Furthermore, De Silva, Rajakaruna \& Bandara (2008) found that inadequate safety precautions, non-implementation of rules, limited funds, deficient knowledge and unqualified officers cause unexpected accidents in the construction industry. Additionally, the low educational level of many construction workers is a barrier to improve safety at construction sites.

Lubega et al (2000) mentioned that the cause of accident in construction site is directly related to inadequate of safety regulation, no force to use the regulation in site, no safety consideration by personnel on site, no encourage professional people to work in site, mechanical problem of construction machinery and equipment, and chemical or physical disturbance Tambun, Murwaningsari \& Mayangsari (2018).

The challenge to this issue is to determine the predominant factors and develop a benchmark for measuring safety management in the construction industry to foster safe working environments at construction sites. The key factors influencing safety management have not previously been the focus of research, and to date, no safety management framework has been formulated as a benchmark for construction safety management in developing countries.

\section{Research Method}

Data are collected through a self-administered questionnaire distributed by hand to 100 contractors working within construction site of SESCO Sub-Station Project in Balingan, Sarawak, Malaysia. However, out of the 100-questionnaire distributed, 95 were useable. The questionnaire was categorized in six sections. In Section A, it consists of information regarding the respondent's demographic characteristics such as age, educational background and experiences. In Section B, it contains variables relating to working environment. Whereas education and training among construction workers is in Section C, with Section D consists PPE with weather condition is in Section E. An overall perception on safety performance among respondents is listed in Section F. For Section B to F, a five-point Likert's scale was suggested because it allows accurate assessment of opinions, which are often conceptualized in terms of gradation.

\section{Data Analysis and Findings}

\subsection{Respondents' Profile}

Gender analysis found that 11 percent respondents were female compared to 88.6 percent were male. A gender biases is not an issue in this study as well in the organization but the nature of work which needed masculine personal to deliver their daily task in construction sector. There were seven age groups among respondents which range from less than 25 to more than 50 years old. The pattern shows that age group concentrations were ranging from 26 to 35 years old, which accumulated almost half or 48.8 percent of them. Respondents with age 25 years old and less are at 17.1 percent and aged above 50 years old as at 5.7 percent. In depth analysis on number of years working experiences with the studied organization revealed that 40.0 percent of them were less than 3 years and 37.1 percent for 4 to 6 years and the remaining 22.9 percent for 7 to 10 years of experiences. Academic backgrounds were divided into three categories, namely primary school, secondary school, and tertiary level. The study found that 51.4 percent of respondents were secondary school leavers followed the primary school levers at 31.4 percent and 17.1 percent were graduated from higher learning institute. Monthly salary paid is based on monthly basis received by respondents. There were divided into six categories, with range about RM1000 for each category. Almost half of them or 48.6 percent of them earned between RM1001 to RM2000. Among the senior employees such as supervisor, engineer and manager earned more than RM4000 as proved by 11.5 percent, whereas among junior support staff is less than RM1000 at 20.0 percent. Ethic composition revealed that slightly a third (34.3\%) were Iban, followed by Malays/Melanau/Jawa at 20.0 percent and Bidayuh (14.3\%). Other ethnic consists of Chinese (17.1\%) and Orang Ulu (14.3\%).

Research Objective 1: To investigate the relationship between Working Environment with Safety Performance among construction workers at SESCO Sub-Station, Balingian, Sarawak. 
Table 1. Pearson's Correlation Analysis

\begin{tabular}{llcc}
\hline & & Environmental Factor & Safety Performance \\
\hline Environmental & Pearson Correlation & 1 & .248 \\
Factor & Sig. (2-tailed) & & .151 \\
& $\mathrm{~N}$ & 95 & 95 \\
\hline Safety & Pearson Correlation & .248 & 1 \\
Performance & Sig. (2-tailed) & .151 & \\
& $\mathrm{~N}$ & 95 & 95 \\
\hline
\end{tabular}

In the above table, Pearson's $r$ is 0.248 . This number is quite far from 1 . For this reason, it can be concluded that there is significant relationship between environmental factor and safety performance. In addition, Pearson's $r$ was shown as positive which indicates that as one variable increases in value, the second variable also increase in value and as one variable decrease in value, the second variable also decrease in value. Based on the result, it is proven that environmental factors and safety performance has a significant and positive relationship. Since the Sig (2-Tailed) value is not less than or equal to $.05(\mathrm{p}=0.151)$ we can conclude that there is a statistically no significant relationship between the two variables.

Research Objective 2: To evaluate the relationship between Education and Training with Safety Performance among construction workers at SESCO Sub-Station, Balingian, Sarawak.

Table 2. Pearson's Correlation Analysis

\begin{tabular}{llcc}
\hline & & Education \& Training & Safety Performance \\
\hline Education \& & Pearson Correlation & 1 & $.352^{*}$ \\
Training & Sig. (2-Tailed) & & .038 \\
& $\mathrm{~N}$ & 95 & 95 \\
\hline Safety & Pearson Correlation & $.352^{*}$ & 1 \\
Performance & Sig. (2-Tailed) & .038 & \\
& $\mathrm{~N}$ & 95 & 95 \\
\hline
\end{tabular}

The Table 2 above demonstrates a significant relationship between education \& training and safety performance. The outcome shows that there is relatively low correlation, which means there is a small relationship of 0.352 . Pearson's $r$ was shown as positive which shows that as one variable increases in value, the second variable also increase in value and vice versa. This result proved that education \& training and safety performance has a small and positive relationship. Sig (2-Tailed) value is less than or equal to $.05(\mathrm{p}=0.038)$. This imply that there is a statistically significance relationship between the two variables.

Research Objective 3: To measure the relationship between PPE with safety performance among construction workers at SESCO Sub-Station, Balingian, Sarawak.

Table 3. Pearson's Correlation Analysis between respondents' perception on PPE according to the safety performance

\begin{tabular}{llcc}
\hline & & PPE & Safety Performance \\
\hline PPE & Pearson Correlation & 1 & .437 \\
& Sig. (2-Tailed) & & .032 \\
& $\mathrm{~N}$ & 95 & 95 \\
\hline Safety Performance & Pearson Correlation & .437 & 1 \\
& Sig. (2-Tailed) & .032 & \\
& $\mathrm{~N}$ & 95 & 95 \\
\hline
\end{tabular}


The above table shows a significant relationship between PPE and safety performance. In addition, the relationship between the two variables is relatively low correlation because the result is 0.437 . Pearson's $r$ was shown as positive which indicates that as one variable increases in value, the second variable also increase in value and vice versa. This proven that PPE and safety performance has a positive relationship. Since the Sig (2-Tailed) value is less than or equal to $.05(\mathrm{p}=0.032)$ it is conclude that there is a statistically significance between the two variables.

The statistical technique used to analyze the data below is multiple regression technique.

Research Objective 4: To identify the variable with the most influence on safety performance among construction workers at SESCO Sub-Station, Balingian, Sarawak.

Table 4. Standardized coefficient based on beta value

\begin{tabular}{ccccc}
\hline & \multicolumn{2}{c}{ Coefficient* } & & \\
\hline & Standardized Coefficient & & \\
\cline { 2 - 3 } Model 1 & Beta & $\mathrm{t}$ & Sig. \\
\hline (Constant) & & .370 & .713 \\
Environmental Factor & .341 & 3.958 & .005 \\
Education \& Training & .082 & .691 & .493 \\
PPE & .471 & & 2.946 & .000 \\
\hline
\end{tabular}

a. Dependent Variable: Mean Safety Performance

The result on Table 4 shown above signifies that all the independent variables had relationship with the dependent variable. According to Sekaran 2010, the significant below of $p<0.05$ is generally accepted conventional level in social science research. The finding shows that significant level for variable name Environmental Factor and PPE is significant with $\mathrm{p}$-value is less than $0.05(\mathrm{p}=0.005 ; \mathrm{p}=0.000)$. However, as for variable name Education \& Training, the significant level is more than $0.05(\mathrm{p}=0.493)$ which signifies that this variable is not significant to the study. Based on the standardized coefficients, the variable name PPE is found to have the highest Beta Value of 0.471 followed by Environmental Factor with 0.341 and Education \& Training with 0.082. This estimation of Beta Value notifies the amount of increase Safety Performance would be predicted by a one-unit increase in the predictor namely PPE, and Environmental Factor. Thus, it shows that PPE leads to the most critical effect size towards safety performance among construction workers at SESCO Sub-Station, Balingian, Sarawak.

Table 5. Model summary of regression

\begin{tabular}{ccccc}
\hline Model & $\mathrm{R}$ & R Square & $\begin{array}{c}\text { Model Summary } \\
\text { Adjusted R Square }\end{array}$ & Std. Error of the Estimate \\
\hline 1 & .563 & .318 & .308 & .325 \\
\hline
\end{tabular}

a. Predictors: (Constant), Environmental, Education \& Training, PPE

b. Dependent Variable: Safety Performance

The linear regression test of the model disclosed that $\mathrm{R}$ Square of the model is 0.318 . It illustrates that $31.8 \%$ of the variance in safety performance among construction workers at Sesco Sub-Station, Balingian, and Sarawak has been significantly explained by Environmental Factor, Education \& Training and PPE in this research. Meanwhile, the remaining $68.2 \%$ cannot be explained. That means there were other factors that can determine the safety performance among construction workers at Sesco Sub-Station, Balingian, Sarawak.

\section{Conclusion and Recommendation}

The major purpose of this study is to find out the factor that may influence safety performance to support study constructs adopted from Ratnawills (2010), which was developed by Hayes et al (1998), influence safety performance specifically on training and education with addition to PPE. Reliability coefficients of Cronbach's Alpha appeared to 
be obtained higher than 0.7 for each study construct, suggesting that the research instruments were appropriate indicators of their respective construct (Miller 1991). Correlation analysis was done to examine the relationship between study variables. However, the strength of relationship were vary which were proved by the Pearson's coefficient or ( $\mathrm{r}$ ) value in the analysis.

The finding in this study found that PPE is the key factor that contributes to the safety performance among the construction workers at SESCO Sub Station, Balingian Sarawak. It shows that the construction workers were aware about the important of PPE in their work. This is evidence by the fact that more than $60 \%$ of the workers have more than three year working experiences. These experienced workers had already been exposed to the working environment and condition; hence, they might have some knowledge about the important of PPE to protect themselves during working.

Observing the above mentioned factors, it can be concluded that adequate, timely and appropriate use of PPE is essential as well as it contribute extensively to improve the safety performance of the industry. Hence, this is an aspect that requires further insight, especially as to why an appreciable proportion of construction workers do not wear PPE. This diagnosis will be significant, in particular, towards developing strategic recommendations for improved usage of PPE in the industry. This study only covers a small proportion of construction workers in a designated construction site which is located in the rural area of Sarawak. A further study may give insights towards understanding why and how PPE affect the safety performance among the construction workers in different geographical setting.

\section{References}

Abdul Hamid, A. R., Abd Majid, M. Z., \& Singh, B. (2008). Causes of accidents at construction sites. Malaysian Journal of Civil Engineering 20(2), 242-259.

Al-Amoudi, W. A. (1997). Assessment of Safety Level in Performing Building Maintenance Work in Saudi Arabia. Unpublished Master Thesis, King Fahd University of Petroleum \& Minerals, Dhahran, Saudi Arabia.

Aziz, M. A. (2009). SOCSO Initiatives Towards Continous Improvement of OSH in SMEs. Paper presented at Seminar of Occupational and Health in SME Sectors, ASSET, Bangi, Selangor, Malaysia.

Badri, A., Gbodossou, A., \& Nadeau, S. (2012). Occupational health and safety risks: towards the integration into project management. Saf Sci., 50(2), 190-8. https://doi.org/10.1016/j.ssci.2011.08.008

Bansal V. K. (2011). Application of geographical information systems in construction safety planning. International Journal of Project Management, 29(1), 66-77. https://doi.org/10.1016/j.ijproman.2010.01.007

Chang, H., \& Yeh, C. (2005). Factors affecting the safety performance of bus companies the experience of Taiwan bus deregulation. Safety Science, 43, 323-344. https://doi.org/10.1016/j.ssci.2005.07.001

Cherrington, D.J. (1995). The management of human resources (4th ed.). New Jersey: Prentice Hall.

De Silva, N., Rajakaruna, R.W.D.W.C.A.B., \& Bandara, K.A.T.N. (2008). Challenges faced by the construction industry in Sri Lanka. Proceedings: CIB International Conference in Building Education and Research. Sri Lanka, 1023-1032.

Duijm, N. J., Fie'vez, C., Gerbec, M., Hauptmanns, U., \& Konstandinidou, M. (2008). Management of health, safety and environment in process industry. Safety Science, 46, 908-920. https://doi.org/10.1016/j.ssci.2007.11.003

Gangolells, M., Casals, M., Forcada, N., Roca, X., \& Fuertes, A. (2010). Mitigating construction safety risks using prevention through design. Journal of Safety Research, 41, 107-122. https://doi.org/10.1016/j.jsr.2009.10.007

Goetsch, D. L. (2008). Occupational Safety and Health for Technologist, Engineers and Managers (6th ed.). New Jersey: Prentice-Hall.

Griffith, M.A., \& Neal, A. (2000). Perceptions of safety at work: A framework for linking safety climate to safety performance, knowledge and motivation. J. Occup. Health Psychol., 5, 347-358. https://doi.org/10.1037/1076-8998.5.3.347

Gunawan, D. (2006). Behavioral Base Safety Factors and Safety Performance in Chemical Industry in Indonesia. PhD thesis, Universiti Utara Malaysia: College of Business.

Hahn, S. E., \& Murphy, L. R. (2008). A Short Scale for measuring safety climate. Safety Science, 46, 1047-1066. https://doi.org/10.1016/j.ssci.2007.06.002

Hakkinen, K. (1995). A learning-by-doing strategy to improve top management involvement in safety. Safety Science, 20(2-3), 299-304. https://doi.org/10.1016/0925-7535(95)00028-F 
Haslam, R. A., Hide, S. A., Gibb, A. G. F., Gyi, D. E., Pavitt, T., Atkinson, S., \& Duff, A. R. (2005). Contributing factors in construction accidents. Applied Ergonomics, 36, 401-415. https://doi.org/10.1016/j.apergo.2004.12.002

Hayes, B., Perander, J., Smecko, T., \& Trask, J. (1998). Measuring Perceptions of Workplace Safety: Development and Validation of the Work Safety Scale. Journal of Society Research, 29, 145-161. https://doi.org/10.1016/S0022-4375(98)00011-5

Hinze, J, \& Gambatese, J. (2003). Factors that Influence Safety Performance of Specialty Contractors. J ConstrEng Manage, 129, 159-164. https://doi.org/10.1061/(ASCE)0733-9364(2003)129:2(159)

Inyang, B. J. (2008). Bridging the Existing Gap between Human Resource Management Function (HRMF) and Enterprise Management (EM) in Nigeria. Pakistan Journal of Social Sciences, 5(6), 534-544.

Jannadi, O. M. (2008). Risks Associated With Trenching Works in Saudi Arabia. Journal of Building and Environment, 43, 776-781. https://doi.org/10.1016/j.buildenv.2007.01.034

Johnston, J. J., Catteledge, G. T. T., \& Collins, J. W. (1994). The Efficacy of Training for Occupational Injury Control. Occupational Medicine: State of the Arts Reviews, 9(2), 147-158.

Kartam, N. A., Flood, I., \& Koushki, P. (2000). Construction safety in Kuwait: Issues, procedures, problems and reccomendations. Safety Science, 36, 163-184. https://doi.org/10.1016/S0925-7535(00)00041-2

Kelloway, E. K., \& Francis, L. (2008). Management of Occupational Health \& Safety (4th ed.). Ontario: Nelson Education Ltd.

Koehn, E., Kothari, R. K., \& Pan, C-S. (1995). Safety in Developing Countries: Professional and Bureaucratic Problems. Journal of Construction Engineering and Management, 121(3), 261-265. https://doi.org/10.1061/(ASCE)0733-9364(1995)121:3(261)

Ling, F.Y.Y., Liu, M., \& Woo, Y.C. (2009). Construction fatalities in Singapore. International Journal of Project Management, 27(7), 717-26. https://doi.org/10.1016/j.ijproman.2008.11.002

Lubega, H. A., Kiggundu, B. M., \&Tindiwensi, D. (2000). An Investigation into the Causes of Accidents in the Construction Industry in Uganda. 2nd International Conference on Construction in Developing Countries: Challenges Facing the Construction Industry in Developing Countries, pp1-12.

Meams, K., Whitaker, S. M., \& Flin, R. (2003). Safety Climate, Safety Management Practice and Safety Performance in Offshore Environments. Safety Science, 4(8), 641-680. https://doi.org/10.1016/S0925-7535(02)00011-5

Miller, D. C. (1991). Handbook of research design and social measurement (5th ed.). Newbury Park, CA: Sage.

Neal, A., Griffin, M. A., \& Hart, P. M. (2000). The impact of organizational climate on safety climate and individual behavior. Safety Science, 34, 99-109. https://doi.org/10.1016/S0925-7535(00)00008-4

Obay, L. A. (2018). The Capital Structure Choice: Evidence of Debt Maturity Substitution by GCC Firms. Asian Economic and Financial Review, 8(11), 1298-1312. https://doi.org/10.18488/journal.aefr.2018.811.1298.1312

Obeng, G. (2018). Value Added Tax and Vat Flat Rate Scheme in Ghana, Any Cascading Implications. Asian Development Policy Review, 6(4), 213-225. https://doi.org/10.18488/journal.107.2018.64.213.225

Obi, M. N., \& Okekeokosisi, J. (2018). Extent of Implementation of National Entrepreneurship Curriculum in Tertiary Institutions as Perceived by Educators. American Journal of Education and Learning, 3(2), 108-115. https://doi.org/10.20448/804.3.2.108.115

Pinto, A., Nunes, I. L., \& Ribeir, R. A. (2011). Occupational risk assessment in construction industry: overview and reflection. Saf. Sci., 49(5), 616-24. https://doi.org/10.1016/j.ssci.2011.01.003

Ratnawills, Md. A. (2010). Understanding Employees Compliance with Safety Behaviour in A Telecommunication Industry. Masters' Thesis. Sintok: University Utara Malaysia.

Reese, C. D., \& Eidson, J. V. (1999). OSHA Construction Safety and Health. Lewis Publishers.

Roughton, J. E., \& Mercurio, J. J. (2002). Developing an Effective Safety Culture: A Leadership Approach. Woodburn: Butterworth-Heinemann. https://doi.org/10.1016/B978-075067411-9/50008-6

Sawacha, E., Naoum, S., \& Fong, D. (1999). Factors affecting safety performance on construction sites. International Journal of Project Management, 17(5), 309-315. https://doi.org/10.1016/S0263-7863(98)00042-8 
Shahrinaz, I., Jati, K., \& Bibi, S. S. N. (2015). Do Attitude, Trust and Knowledge have relationship towards Purchase intention of Manufactured Halal Food Product?. Proceeding of International Islamic Borneo Conference VIII, Universiti Islam Sultan Sharif Ali (UNISSA), Brunei Darussalam, 2nd - 3rd September 2015.

Sundjo, F., \& Aziseh, F. (2018). An Empirical Investigation into the Key Drivers of Economic Performance in the CEMAC Zone: A Panel Corrected Standard Errors Approach. International Journal of Business, Economics and Management, 5(6), 189-200. https://doi.org/10.18488/journal.62.2018.56.189.200

Suryanto, T., Haseeb, M., \& Hartani, N. H. (2018). The correlates of developing green supply chain management practices: Firms level analysis in Malaysia. International Journal of Supply Chain Management, 7(5), 316.

Tambun, S., Murwaningsari, E., \& Mayangsari, S. (2018). The Effect of Accounting Information on Stock Price Predictions Through Fluctuation of Stock Price, Evidence From Indonesia. Journal of Accounting, Business and Finance Research, 4(1), 20-27. https://doi.org/10.20448/2002.41.20.27

Teo, E.A.L., Ling, F.T.Y., \& Chong, A.F.W. (2005). Framework for Project Managers to Manage Construction Safety. International Journal of Project Management, 23(4), 329-341. https://doi.org/10.1016/j.ijproman.2004.09.001

Vrendenburgh, A. G. (2002). Organizational Safety: Which Management Practices are Most Effective in Reducing Employee Injury Rates?. Journal of Safety Research, 33(2), 259-276. https://doi.org/10.1016/S0022-4375(02)00016-6 